Note: This is a preprint of a paper being submitted for publication. Contents of this paper should not be quoted nor referred to without permission of the author(s).

To be published in Proceedings of the First International Workshop on Plasma Source Ion Implantation, University of Wisconsin, August 4-6, 1993.

\title{
POTENTIAL APPLICATIONS OF FUSION NEUTRAL BEAM FACILITIES FOR ADVANCED MATERIAL PROCESSING
}

\author{
J. M. Williams, C. C. Tsai, W. L. Stirling, and J. H. Whealton \\ Oak Ridge National Laboratory, Oak Ridge, TN
}

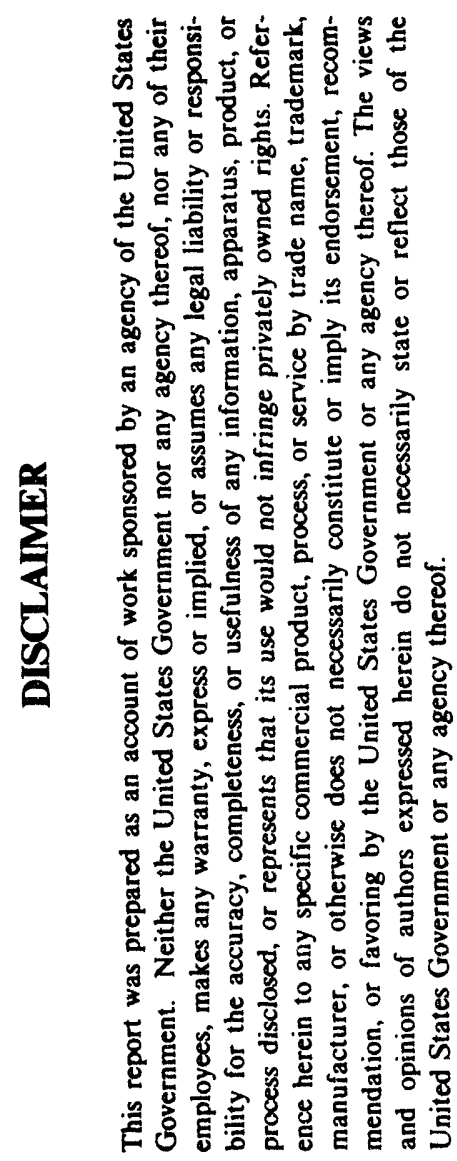

\begin{abstract}
"The submitted manuscript has been authored by a contractor of the U.S. Government under contract No. DEAC5-84OR21400. Accordingly, the U.S. Government retains a nonexclusive, royalty-free license to publish or reproduce the putlished form of this contribution, or allow others to do so, for U.S. Government purposes."
\end{abstract}

Prepared by the

Oak Ridge National Laboratory

Oak Ridge, Tennessee 37831

managed by

MARTIN MARIETTA ENERGY SYSTEMS, INC.

for the

U.S. DEPARTMENT OF ENERGY

under contract DE-AC05-84OR21400

January 1994






\title{
POTENTIAL APPLICATIONS OF FUSION NEUTRAL BEAM FACILITIES FOR ADVANCED MATERIAL PROCESSING*
}

\author{
J. M. Williams, C. C. Tsai, W. L. Stirling and J. H. Whealton \\ Oak Ridge National Laboratory \\ Oak Ridge, Tennessee 37831
}

\begin{abstract}
Surface processing techniques involving high energy ion implantation have achieved commercial success for semiconductors and biomaterials. However, wider use has been limited in good part by economic factors, some of which are related to the line-of-sight nature of the beam implantation process. Plasma source ion implantation (or plasma immersion ion implantation) is intended to remove some of the limitations imposed by directionality of beam systems and also to help provide economies of scale. The present paper will outline relevant technologies and areas of expertise that exist at Oak Ridge National Laboratory in relation to possible future needs in materials processing. Experience in generation of plasmas, control of ionization states, pulsed extraction, and sheath physics exists. Contributions to future technology can be made either for the immersion mode or for the extracted beam mode. Existing facilities include the High Power Test Facility, which could conservatively operate at $1 \mathrm{~A}$ of continuous current at $100 \mathrm{kV}$ delivered to areas of about $1 \mathrm{~m}^{2}$. Higher instantaneous voltages and currents are available with a reduced duty cycle. Another facility, the High Heat Flux Facility can supply a maximum of $60 \mathrm{kV}$ and currents of up to $60 \mathrm{~A}$ for $2 \mathrm{~s}$ on a $10 \%$ duty cycle. Plasmas may be generated by use of microwaves, radio-frequency induction or other methods and plasma properties may be tailored to suit specific needs. In addition to ion implantation of large steel components, foreseeable applications include ion implantation of polymers, ion implantation of $\mathrm{Ti}$ alloys, $\mathrm{Al}$ alloys, or other reactive surfaces.
\end{abstract}

*Research managed by the Office of Fusion Energy, U.S. Department of Energy, under contract DE-AC05-84OR21400 with Martin Marietta Energy Systems, Inc. 


\section{INTRODUCTION}

In principle, materials processing techniques involving high energy ion implantation and related high energy processes such as ion-beam assisted deposition (IBAD) have many attractive features. These features include, but are not limited to, the following:

- chemical flexibility--concentrations of dopants and combinations of dopants and targets that are not accessible via ordinary chemistry can be used.

- chemical controllability via ion dosimetry

- integrity and adhesion of treated layers

- possibility of low temperature processing

- cleanliness and preservation of surface finish and tolerance

- minimization of process feed material, and environmental acceptability.

Because of these possible advantages a large body of research on ion processing of materials has been performed in the last several years. Despite this effort, the use of ion implantation as a commercial process remains limited almost entirely to semiconductors, biomaterials, and a few other products of high specific materials value. It is generally accepted that wider use of ion implantation has been limited more by costs than by any other factor [1].

The Plasma Source Ion Implantation (PSII) technology [2] has arisen in response to the need for more cost effective ion implantation processes. The PSI technology is an outgrowth of fusion energy technology, for which large neutral energetic atomic beams are needed for heating of magnetically confined plasmas. The essential feature of the PSII technique, in comparison with the ion beam technique, is that the product (target) is immersed within the plasma, or ion source. The product is a field terminal, in that ions are extracted directly from the plasma to the product. For the present article, the acronym PSII will be used to refer to the immersion technique in contrast to the beam technique. 
The plasma immersion technique is receiving considerable private and public investment, and is the main topic of the present conference. An alternative use of fusion energy ion production technology is to use the multipole (or "bucket") source in the extracted beam or line-of-sight (LOS) mode. Conceptually this is the same as any other beam technique, except that economies of scale could result from the pure size of the ion sources, possible modularization, and the fact that the ions are not magnetically analyzed. At present this latter approach is receiving less attention than the immersion approach. The leader in application of the beam approach has been Deamaley, who has constructed a large implanter using a bucket source at Harwell, UK [3]. A somewhat similar approach has made use of ion propulsion technology for materials processing [4].

Because of its experience in development of plasma generators, ion sources, and neutral beam injectors [5,6], the Fusion Energy Division of Oak Ridge National Laboratory (ORNL) can contribute to either approach. The present paper will identify existing facilities, contributions, and capabilities. Possible advantages and disadvantages of the immersion concept and the beam concept will be identified. Our conclusion will be that both techniques will probably be needed for ion processing at industrial scale, depending on such factors as material, implantation parameters and interfacing with other manufacturing processes.

\section{BEAM TECHNOLOGY}

The existing ORNL broad beam technology is a result of the experience mentioned above. The duoPIGatron positive ion source was developed for producing $\mathrm{cw}$ hydrogen ion beams of $600 \mathrm{keV}$ and $0.3 \mathrm{~A}$ by Kelly [7] and Morgan [8] in the 1960s. Generated by PIG (or reflex) discharges in the duoPIGatron ion source, the positive hydrogen ions are extracted and accelerated through an ion accelerator with accel-decel electrodes. Further development of duoPIGatron ion sources for producing multimegawatt neutral beams for heating plasmas was carried out in the 1970s and 1980s by Stirling [9], Davis [10], Tsai [11], Haselton [12], and Whealton [13]. 
Figure 1 shows a sketch of the ion source and associated power supplies. The source plasma is composed of a cathode plasma and an anode plasma. Similar to a duoplasmatron ion source, the cathode plasma between the hot cathode and intermediate electrode supplies the ionizing electrons necessary to produce the anode plasma. The electrons that are accelerated through the double sheath between the two plasmas are constrained by the axial magnetic fields and oscillate between anode 1 and the plasma grid (or target cathode) thereby creating an intense PIG discharge and producing a dense anode plasma [11]. Axial magnets on the chamber walls of anode 2 form a multipole magnetic line cusp field to improve plasma confinement, stability, and uniformity [9]. In such sources high density $\left(\sim 10^{12} \mathrm{~cm}^{-3}\right)$ hydrogen plasmas are uniformly distributed over the several hundred square centimeters of extraction surface; $30 \mathrm{~cm}$ diameter for round geometries and $13 \mathrm{~cm} \mathrm{x} 43 \mathrm{~cm}$ for rectangular geometries (Fig. 2). Hydrogen plasmas with current densities of $0.5 \mathrm{~A} / \mathrm{cm}^{2}$ are capable of supplying an ion current up to $100 \mathrm{~A}$ to accelerators in which multiaperture grids have been designed and optimized theoretically and experimentally [13]. High energy cw hydrogen ion beams of $600 \mathrm{keV} / 0.3 \mathrm{~A}$ and pulsed $(100 \mathrm{~ms})$ ion beams of $110 \mathrm{kV} / 10 \mathrm{~A}$ were reliably formed $[7,11]$. These plasma sources are readily adaptable to both line of sight and plasma ion implantation applications. The output current for heavier gases scales as the square root of the mass ratio.

Recently, hot cathode plasma sources in the duoPIGatrons have been modified with both a microwave plasma generator [14] and a radio frequency induction plasma generator [15]. The microwave plasma source was developed for plasma processing of microelectronics. Such a microwave multicusp plasma source (Fig. 3) consists of a microwave launcher in a solenoid, and a plasma chamber with multicusp magnetic fields. The solenoid provides an axial magnetic field of 875 gauss in the exit region of the microwave launcher and creates an electron cyclotron resonance (ECR) zone for the $2.45 \mathrm{GHz}$ microwave energy. The electrons gain their kinetic energy in the ECR zone and drift along the divergent magnetic fields into the plasma chamber. The multicusp fields and solenoid fields confine these electrons and ions which are created. This microwave source can create large area, uniform plasmas of any gas or vapor. It has been operated to produce plasmas of argon, helium, hydrogen, oxygen, and argon/oxygen 
mixtures. It is an ideal candidate for creating plasmas for high energy ion implantation equipment, either for PSII or for conventional ion implantation.

The radio frequency induction plasma generator [15] is similar to the ECR source except for the drive frequency and the wave launching mechanism. It too is capable of generating plasmas from reactive gases as well as conventional.

\section{BEAM FACILITIES}

To develop and qualify neutral beam injectors [12] for heating plasmas in magnetic fusion devices, several large, high-power neutral beam test facilities [16] were constructed at ORNL in the 1970s: the High Power Test Facility (HPTF), the High Heat Flux Facility (HHFF) and the MediumEnergy Test Facility (METF). All three were used to develop ion sources that produce hydrogen ion beams of 10 to $100 \mathrm{~A}, 30$ to $120 \mathrm{keV}$, or 0.05 to $30 \mathrm{~s}$; and to qualify neutral beam injectors that inject neutral beams with power ranging from $\sim 100 \mathrm{~kW}$ to multimegawatt levels. Each of these beam facilities can be used for developing large-area ion implantation systems. In the following, we will describe the capability and potential application of two beam facilities, the HHFF and HPTF.

\section{A. $\underline{\text { HHFF }}$}

The HHFF (Fig. 4) is a medium-energy $(<60 \mathrm{keV})$ and large-area $(<1000$ $\mathrm{cm}^{2}$ ) beam facility. It was set up to produce ion beams of hydrogen or other gas compatible with the hot cathode of the ion source. It used a $10-\mathrm{cm}$ duoPIGatron ion source, which was developed to form 40-keV, 10-A, 50-ms hydrogen ion beams that were converted into neutral beams for heating plasmas in ORMAK (an Oak Ridge Tokamak). For developing and qualifying high heat flux ( 1 to $\left.5 \mathrm{~kW} / \mathrm{cm}^{2}\right)$ components, the facility was operated to produce 3-s ion beams with energy up to $26 \mathrm{keV}$, current up to $7 \mathrm{~A}$, and peak power density up to $7 \mathrm{~kW} / \mathrm{cm}^{2}$. For ion implantation applications, the facility may be operated to produce ion beams of any gas over a target area up to $1000 \mathrm{~cm}^{2}$. In fact, the beam energy can be increased up to $60 \mathrm{keV}$ (limited by the high voltage power supply), and $60 \mathrm{~A}$ and $2 \mathrm{~s}$ at 
$10 \%$ duty. The electronics control in this facility offers the flexibility of changing the beam pulse length from $\leq 1 \mathrm{~ms}$ to $2 \mathrm{~s}$ and the duty factor from $\leq 0.001 \%$ to $10 \%$. The vacuum system can be evacuated to a base pressure below 10-6 torr and maintained at pressures below $10^{-4}$ torr during ion beam processing by six $25-\mathrm{cm}$-diam diffusion pumps with a pumping speed of $12,000 \mathrm{~L} / \mathrm{s}$ for hydrogen. The vacuum chamber consists of two cylindrical tanks of $60 \mathrm{~cm}$ in diameter and $120 \mathrm{~cm}$ long. Many vacuum ports with diameters from 20 to $60 \mathrm{~cm}$ provide access for large-area targets or samples and experimental instrumentation. In addition, the well-developed duoPIGatron ion sources can reliably produce ion beams with little need of maintenance. Moreover, the high duty factor (10\%), fast pump down time $(\sim 1 \mathrm{~h})$, flexibility for changing the experimental setup, and low operating cost make this facility very attractive for concept evaluation and technology development.

\section{B. $\underline{\text { HPTF }}$}

The HPTF (Fig. 5, 6) is a high-energy $(\sim 150 \mathrm{kV})$ and large-area $\left(\sim 1 \mathrm{~m}^{2}\right)$ facility. The facility was constructed to develop high-power ion sources for forming hydrogen ion beams with energy up to $150 \mathrm{kV}$ (or $75 \mathrm{kV}$ ), current up to $50 \mathrm{~A}$ (or $100 \mathrm{~A}$ ), pulse length up to $20 \mathrm{~s}$, and duty factor of $10 \%$ [15]. It was operated to develop ion sources for forming ion beams of: $100 \mathrm{~A}, 50 \mathrm{kV}$, and $0.5 \mathrm{~s} ; 10 \mathrm{~A}, 90 \mathrm{kV}$, and $10 \mathrm{~s}$; or $7 \mathrm{~A}, 110 \mathrm{kV}$, and $0.04 \mathrm{~s}$. The generic study on tetrode (four grids) ion accelerators reveals that the transverse power density distribution of ion beams at fixed ion energy can be controlled by changing beam optics, which is a sensitive function of the ratio of electric field in the second gap to that in the first gap of the accelerator. This was done by using a gradient grid modulator in the high voltage supply to vary the applied potential to the second (or gradient) grid of the accelerator. The modulator of the high voltage supply can be operated to form $\leq 100 \mu$ s ion beams at a duty factor variable from $\leq 0.0001 \%$ to $10 \%$.

The HPTF has three one-cubic-meter vacuum tanks and many large ports either one meter square or one meter in diameter. The vacuum tanks are evacuated by roots blowers mechanical pumps, turbomolecular pumps, and two cryopumps, which have a pumping speed approaching one million liters per second for $\mathrm{H}_{2}$, and a base pressure of $\sim 10^{-7}$ torr. Under ion or neutral 
beam development and qualification, the operating pressure is in the middle of the $10^{-6}$ torr range.

These large vacuum tanks can be used to house large-area targets or samples to be implanted by high energy ion beams. The facility can be operated to form $\mathrm{cw}$ nitrogen ion beams up to $\sim 10 \mathrm{~A}$ and $\sim 150 \mathrm{kV}$ and spread beam ions over large target areas up to $1 \mathrm{~m}^{2}$. For example, 1 -A beams at $100 \mathrm{kV}$ could irradiate over 0.1 to $1 \mathrm{~m}^{2}$ targets at 1000 to $100 \mu \mathrm{A} / \mathrm{cm}^{2}$ and implant a dose of $10^{19}$ to 1018 ions $/ \mathrm{cm}^{2}$ in $30 \mathrm{~min}$. in a $\mathrm{cw}$ mode at 100 to $10 \mathrm{~W} / \mathrm{cm}^{2}$ or longer in a pulsed mode. Without modification, existing and reliable ion sources can produce ion beams of various gases compatible with hot cathodes. With a simple modification of replacing the hot cathode plasma generator with an existing microwave plasma generator, these ion sources can be used to form ion beams of reactive gases such as oxygen. The microwave plasma source was developed for plasma processing and was operated to produce plasmas of argon, helium, hydrogen, oxygen, and argon/oxygen mixtures. Thus a flexible and reliable ion beam system can be designed, assembled, installed, and qualified. Usually, ion implantation work is conducted at a very low duty factor in which case volume pumping may be used without operating the cryopumps in the HPTF. Under such an operating mode, the facility has attractive features of fast pump down time, flexibility for changing the experimental setup, and low operating cost.

\section{PLASMA ION IMPLANTATION}

In the present manifestation the systems described above are beam systems. However, both the HHPF and the HPTF are readily adaptable to the PSII type of operation. To do so the target simply has to be mounted by use of an insulating mount capable of withstanding the accelerating voltage (Fig. 5). The assembly can then be immersed into the plasma source, which can then be either ECR [14] or RFI [15] driven. The sources can be designed and operated to produce plasmas of any gas or vapor. The operating pressure and applied power are used to control plasma density.

Probably the most difficult aspect of the PSII technique is voltage hold-off on the target, while maintaining the desired sheath around the surface. 
Simulation of the sheath physics in a self-consistent treatment is the topic of another paper in the present conference [17].

\section{APPLICATIONS}

Clearly the capabilities of the equipment described above seem primarily suited to processing of materials on a fairly large scale. Effective utilization of this technology depends on expansion of ion implantation markets above existing levels. There are a number of materials science developments and other factors, which together with reduced costs, could stimulate wider acceptance of ion implantation.

Because of the need to preserve the environment and meet regulatory requirements, there is a strong move toward "dry" or vacuum surface processing techniques [18]. Such techniques in general have minimal feed material and minimal liquid wastes. Ion implantation is, in one sense, a competitor of other dry coating $s$ techniques, but would also be compatible in certain multipurpose manufacturing technologies. One need is to reduce use of hexavalent chromium (chrome plating). Because of the ability to add substantial matter, chrome plating is needed for many expensive industrial components as a rebuild technique where wear has occurred. Ion implantation could help by reducing the thickness of plate needed for given lifetimes, or by being compatible in an Ion Beam Assisted Disposition (IBAD) process with another dry deposition technique for $\mathrm{Cr}$ (probably magnetron sputtering). It is now well accepted that nitrogen ion implantation of chrome plate produces striking tribological benefits.

In general, large steel manufacturing components are good candidates for surface hardening techniques for several reasons, including: (1) difficulty in quench hardening, (2) expense of surface treatment is offset by use of inexpensive core alloy, (3) the need for good tolerance and surface finish on many such components.

Ion implantation of mechanical components of reactive metals, such as alloys of $\mathrm{Ti}$ or $\mathrm{Al}$ seems favored by a number of factors. If the passivating oxide on such metals is broken in service, severe consequences such as galling can 
ensue. The same oxide complicates quality assurance for coating techniques because assurance is needed that patches of oxide have not been left before the coating was deposited. Ultimately, IBAD techniques may provide the best coatings. Meanwhile direct ion implantation of $\mathrm{N}$ can easily penetrate native oxide, quality can easily be assured, and the one-step process can be inexpensive. Such implantations usually provide large benefits $[19,20]$. It can be argued that nitrogen ion implantation should be a minimal protocol for many components of $\mathrm{Ti}$ alloys.

There is an increasingly important data base to justify ion implantation treatments for engineering components of polymers, ceramics, and glasses. Research on polymers [21] has shown that ion implantation produces large increases in hardness, increases in chemical resistance and increases in electrical conductivity. Ion implantations of ceramics [22] produces increases in fracture stress, and increases or decreases in near surface hardness, which may be chosen sometimes by design to favor certain tribological behavior, fabricability, etc. Research in ion implantation of glasses is increasing [23].

\section{DISCUSSION}

The advantages of PSII are well accepted, and are the reason for the high degree of interest evidenced by the present conference. These advantages result mainly from the normal incidence of the ions to the surface of the target, so that manipulation of large or complex products is not needed to achieve uniform treatment.

Operation in the beam mode may retain advantages for certain cases, some of which will be identified here:

- Ion implantation of insulators: Ion implantation of insulators, such as polymers and ceramics, would appear simpler with the beam in free flight rather than with the target acting as a terminal. Ability to neutralize the beam might be a further advantage in preventing the target from charging up. 
- Higher voltage ion implantation: Higher voltages may be needed for some products because of the need for deeper treatment or for higher electronic stopping, such as is needed for the polymers [21]. Higher voltages may be more easily managed in the beam mode because of the need for compatible voltage/pulse-time/sheath-thicknesses in PSII. Also radiological safety could be more of an issue in PSII. Secondary and plasma electrons may be accelerated so as to produce $\mathrm{X}$-rays by the high voltage. This problem might be more easily managed in the beam technique because of remoteness of the source from the product.

- Possibility of ion filtering: The beam mode might allow the possibility of some low grade ion filtering, either by lensing or by magnetic analysis at a much lower mass resolution than is used for wafer processors. The concept would be a compromise design which would allow some of the chemical selectivity that has often been an advantage in ion implantation. For example, it might be desirable to implant $\mathrm{Si}$ from $\mathrm{SiF}_{4}$ feed gas while filtering all cracked combinations besides $\mathrm{Si}$.

- Better vacuum and better interfacing with other manufacturing technologies: The beam technique can operate with the product in a better vacuum. There could be a disadvantage for the PSII process for some types of IBAD on some textures because of scattering of the coatoms by plasma gas atoms. Line of sight in a good vacuum works better for low energy co-atoms on surfaces with topographical features with high aspect ratios. As another example of a possible compatibility issue, Nippon Steel Corporation has piloted a dry processing line for sheet steel [24]. The line provides for low energy ion bombardment (for sputter cleaning), ion plating, sputter deposition, and plasma chemical vapor deposition (CVD) to be performed sequentially. Presumably not all of the processes will be used for every product. In this case, the CVD stage is not vacuum compatible with the other processes, and a large differential pumping stage must be provided. A large ion gun could readily be added to such a process line, if needed, and would be compatible on the high vacuum side. 
In view of the above considerations, we believe that escalation of both the beam and PSII technologies to an industrial scale of processing are probably desirable. 


\section{References:}

1. Malcolm E. Boston and Keith O. Legg, Surface and Coatings Technology, 51, 540 (1992).

2. J. R. Conrad, J. L.Radtke, R. A. Dodd, F. J. Worzala, and N. C. Tran, J. Appl. Phys. 62, 4591 (1987).

3. G. Dearnaley, Surface Engineering 2, 213 (1986).

4. P. J. Wilbus and L. O. Daniels, Vacuum 36, 5 (1986).

5. L. A. Berry et al., in Proc. 6th Cunf. of Plasma Physics and Controlled Nuclear Fusion, Vol. 1, p. 49 (1977); H.P. Eubank et al., Phys. Rev. Lett. 43, 270 (1979); M. Murakami et al., Plasma Physics and Controlled Nuclear Fusion Research 1980, Vol. I, (IAEA, Vienna, 19810, p. 377.

6. M. M. Menon et al., J. Appl. Phys. 50, 2484 (1979); Proc. IEEE 69, 1012 (1981); in Proc. 10th Symp. on Fusion Engineering (1983); Nucl. Technol./Fusion, 4, 625 (1983); Rev. Sci. Instrum. 56, 242 (1985).

7. G. G. Kelley, N. H. Lazar, and O. B. Morgan, Nucl. Instrum. and Methods 10, 263 (1961).

8. O. B. Morgan, G. G. Kelley, and R. C. Davis, Rev. Sci. Instrum. 38, 467 (1967); O. B. Morgan in Proc. of the 2nd Symp. on Ion Sources and Formation of Ion Beams, LBL-3399, Lawrence Berkeley Laborator, 1974, paper VI-1.

9. W. L. Stirling, R. C. Davis, O. B. Morgan, and L. D. Stewart, Proc .of the Symp. on Ion Source and Formation of Ion Beams, Brookhaven, October 1971, p. 167; W. L. Stirling, C. C. Tsai, and P. M. Ryan, Rev. Sci. Instrum. 48, 533 (1977); W. L. Stirling, P. M. Ryan, C. C. Tsai, and K. N. Leung, Rev. Sci. Instrum. 50, 102 (1979); W. L. Stirling et al., Appl. Phys. Lett. 35, 104 (1979).

10. R. C. Davis, O. B. Morgan, L. D. Stewart, W. L. Stirling and H. K. Forsen, Rev. Sci. Instrum. 43, 278 (1972); R. C. Davis et al., Rev. Sci. Instrum. 46, 576 (1975). 
11. C. C. Tsai, W. L. Stirling, and P. M. Ryan, Rev. Sci. Instrum. 48, 651 (1977); C. C. Tsai et al., in Proc. 7th Int. Symp. on Engineering Problems of Fusion Research (IEEE, New York, 1977), pp. 278-283; C. C. Tsai et al., in Proc. 5th Topical Meeting on the Technology of Fusion Energy, 1983, Nuclear Technology/Fusion 4, (1983).

12. H. H. Haselton et al., paper 4B6 presented at the IEEE 1977 International Conference on plasma Science, Troy, New York, May 1977; H. H. Haselton et al., in Proc. 8th Int. Conf. on Plasma Physics and Controlled Nuclear Fusion Research, Brussels, Belgium, July 1-10, 1980; H. H. Haselton et al., in Transactions of the 4th Topical Meeting of the American Nuclear Society, King of Prussia, Pennsylvania, 1980, Vol. 1, p. 81.

13. J. H. Whealton, E. F. Jaeger, and J. C. Whitson, J. Comput. Phys. 27, 32 (1978); J. H. Whealton, L. R. Grisham, C. C. Tsai, and W. L. Stirling, J. Appl. Phys. 49(6), 3091 (1978); J. H. Whealton et al., Appl. Phys. Lett. 33(4), 278 (1978); J. H. Whealton, J. Appl. Phys. 53, 2811 (1982); J. H. Whealton, Nucl. Instrum. Meth. 189, 55 (1981); J. H. Whealton and J. C. Whitson, Particle Accelerators 10, 235 (1980).

14. C. C. Tsai, Nucl. Instr. and Meth., B56/57, 1166-1170 (1991).

15. J. B. O. Caughman, Abstract for the 40th National Symposium of the American Vacuum Society, Orlando, FL., Nov 15-19, 1993; J. Hopwood, Plasma Sources Sci. Technol. 1 (1992) 109-116.

16. C. C. Tsai, W. R. Becraft, W. L. Gardner, H. H. Haselton, D. J. Hoffman, M. M. Menon, and W. L. Stirling, in Proc. 11th Symposium of Fusion Engineering, p. 860 (1985).

17. J. H. Whealton, Poster Session, this conference; J. H. Whealton, P. M. Ryan, and R. J. Raridon, Fusion Enginering and Design 12, 121-126 (1990).

18. W. Smyrl, J. W. Halley, G. Hubler, A. Hurd, D. MacDonald, D. Snyder, and J. Williams, Crit. Rev. Surface Chem. 2, 271 (1993).

19. J. M. Williams and R. A. Buchanan, Mat. Sci. Eng. $\underline{69}, 237$ (1985).

20. R. G. Vardiman and R. A. Kant, J. Appl. Phys. $\underline{53}, 690$ (1982). 
21.. E. H. Lee, G. R. Rao, M. B. Lewis, and J. K. Mansur, "Ion beam application for improved polymer surface properties," Nucl. Instr. and Meth. in Physics Research, NIB8042T S, 00 (1992).

22. C. W. White, C. J. MeHargue, P. S. Sklad, L.A. Boatner, and G. C. Farlow, Mater. Sci. Repts. 4, 41 (1989).

23. G. W. Amold, P. Mazzoldi, L. Tramontin, A. Boscolo-Boscoletto, G. Battaglin, Mat. Res. Soc. Proc. 279, 285 (1993).

24. T. Takahashi, Y. Oikawa, T. Komori, I. Ito, M. Hashimoto, Surface and Coatings Technology 51, 522-528 (1992). 
Figure captions.

Fig. 1: Schematic drawing of ion source scheme and circuitry for duoPIGatron positive ion source.

Fig. 2: Photograph of duoPIGatron source with rectangular geometry of $13 \mathrm{~cm} \times 43 \mathrm{~cm}$.

Fig. 3: Schematic of microwave ECR multicusp plasma source.

Fig. 4: Schematic representation of the HHFF facility. The facility can be operated as a medium energy $(55 \mathrm{keV})$, large area $\left(1000 \mathrm{~cm}^{2}\right)$ ion beam implantation system.

Fig. 5: Schematic of the HPTF facility. Target positions for operation, either in the beam mode (LOS) or the immersion mode (PI) are indicated.

Fig. 6: Photograph of the HPTF facility. 
ORNL/OWEVFED 78-397RA

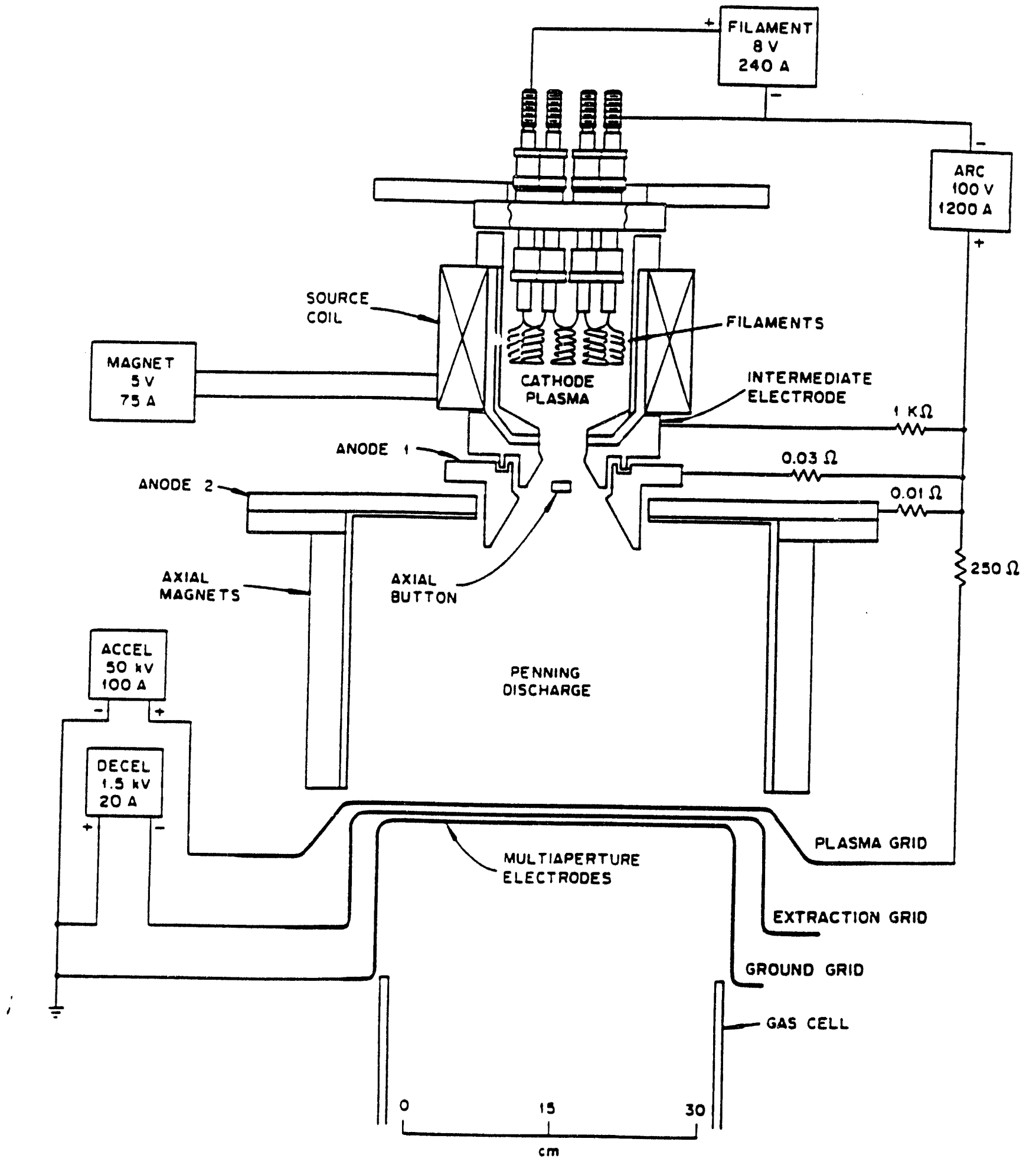

ION SOURCE SCHEME AND CIRCUITRY

FIGURE 1 






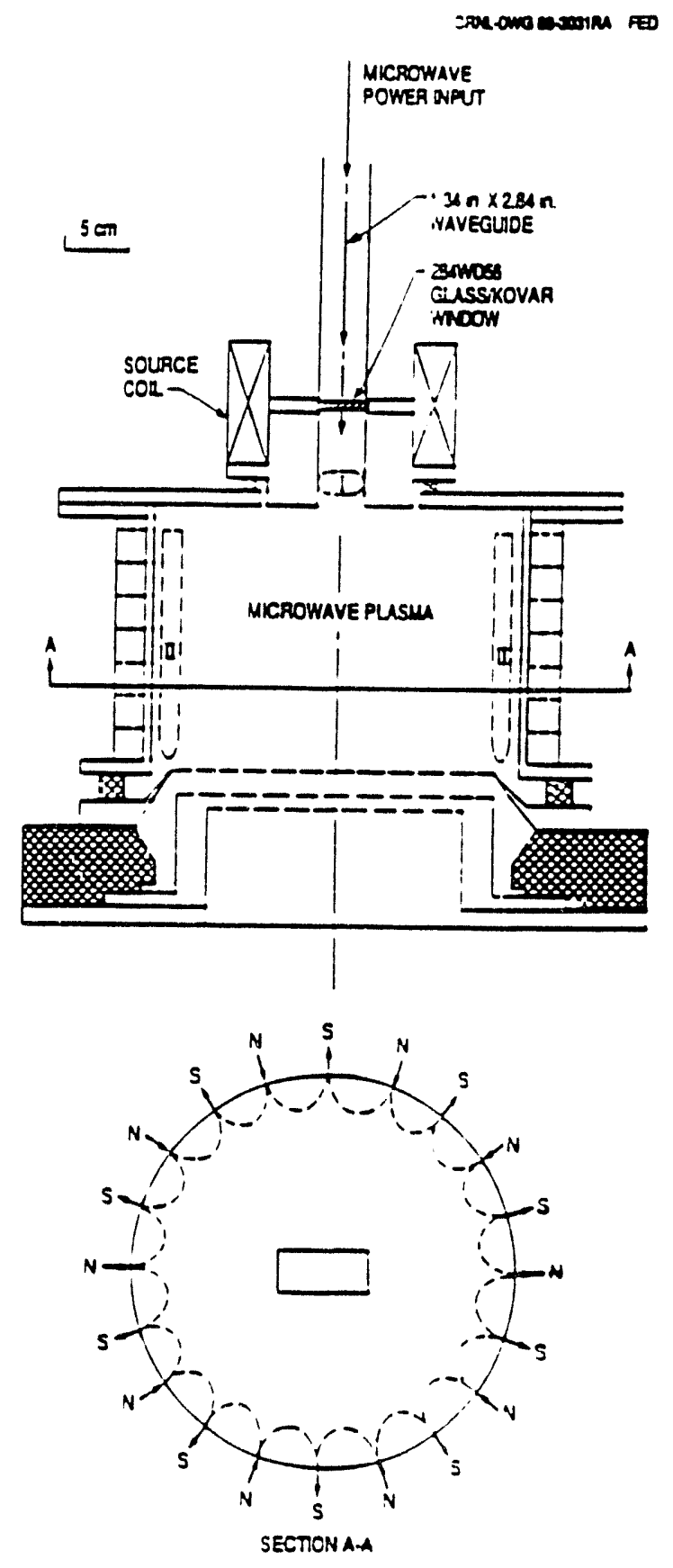

MICROWAVE ECR MULTICUSP =LASMA SOURCE 


\section{HHFF TEST FACILITY}


Figure 4 


\section{HPTF TEST FACILITY}

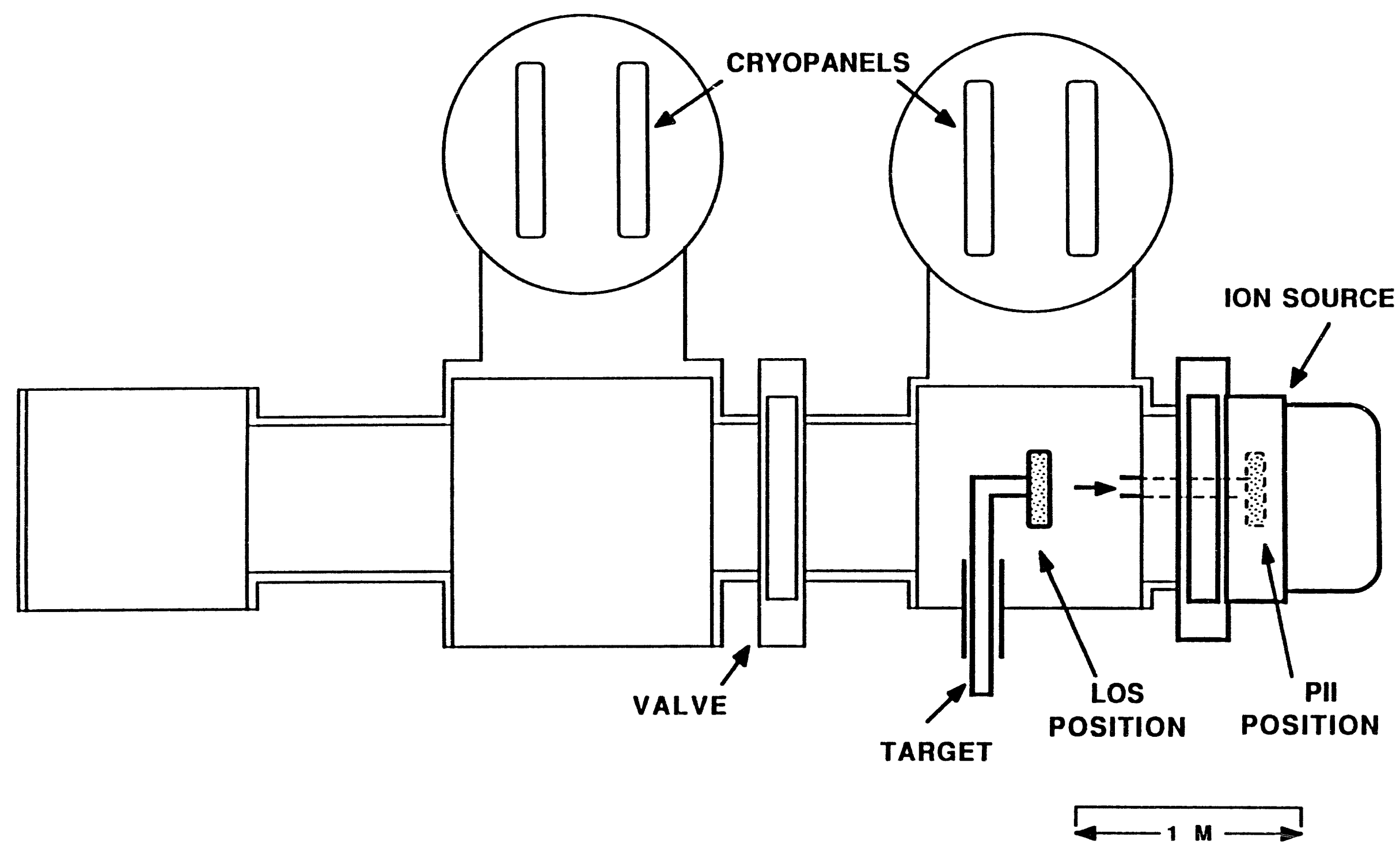

Figure 5 


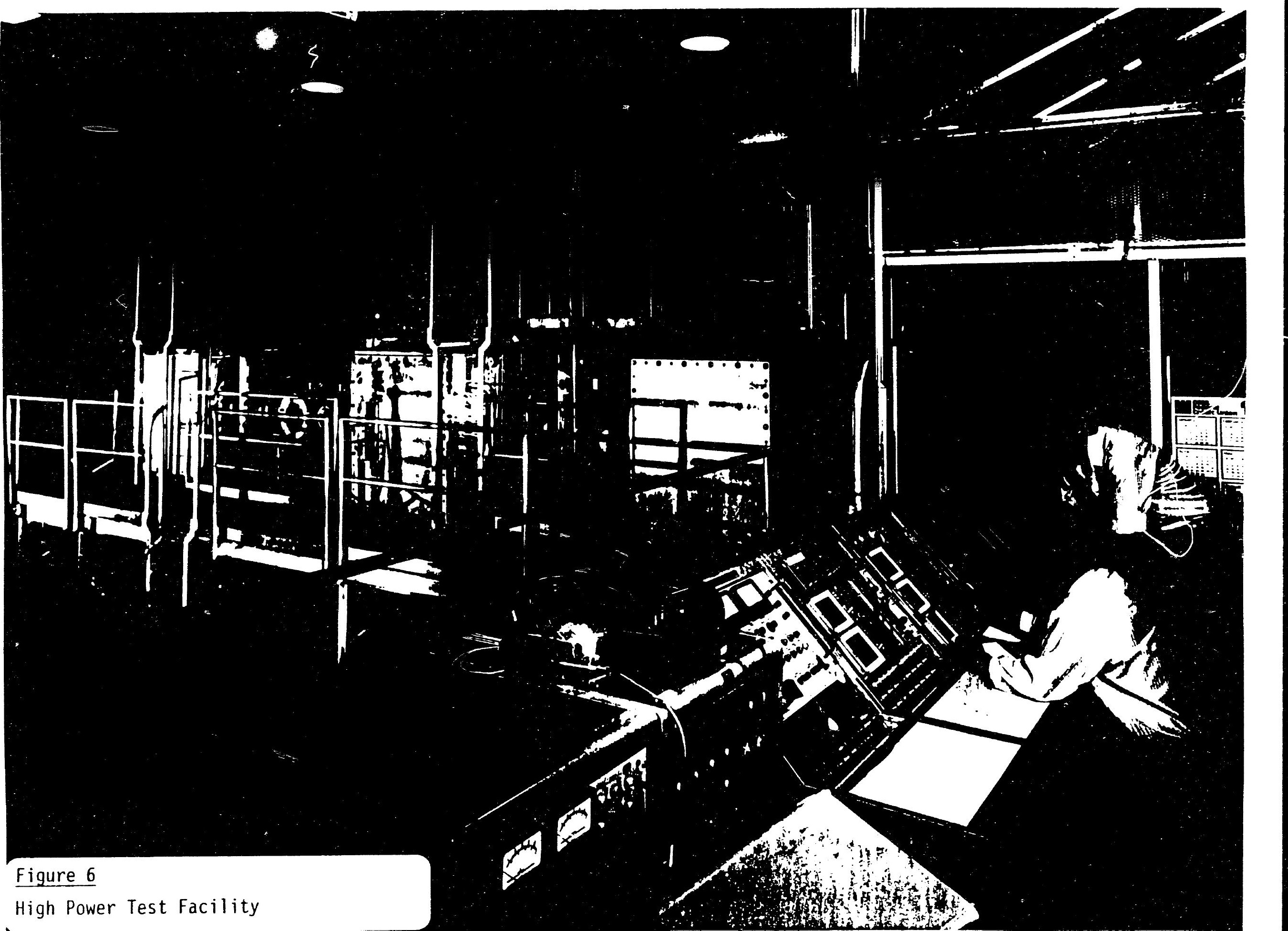



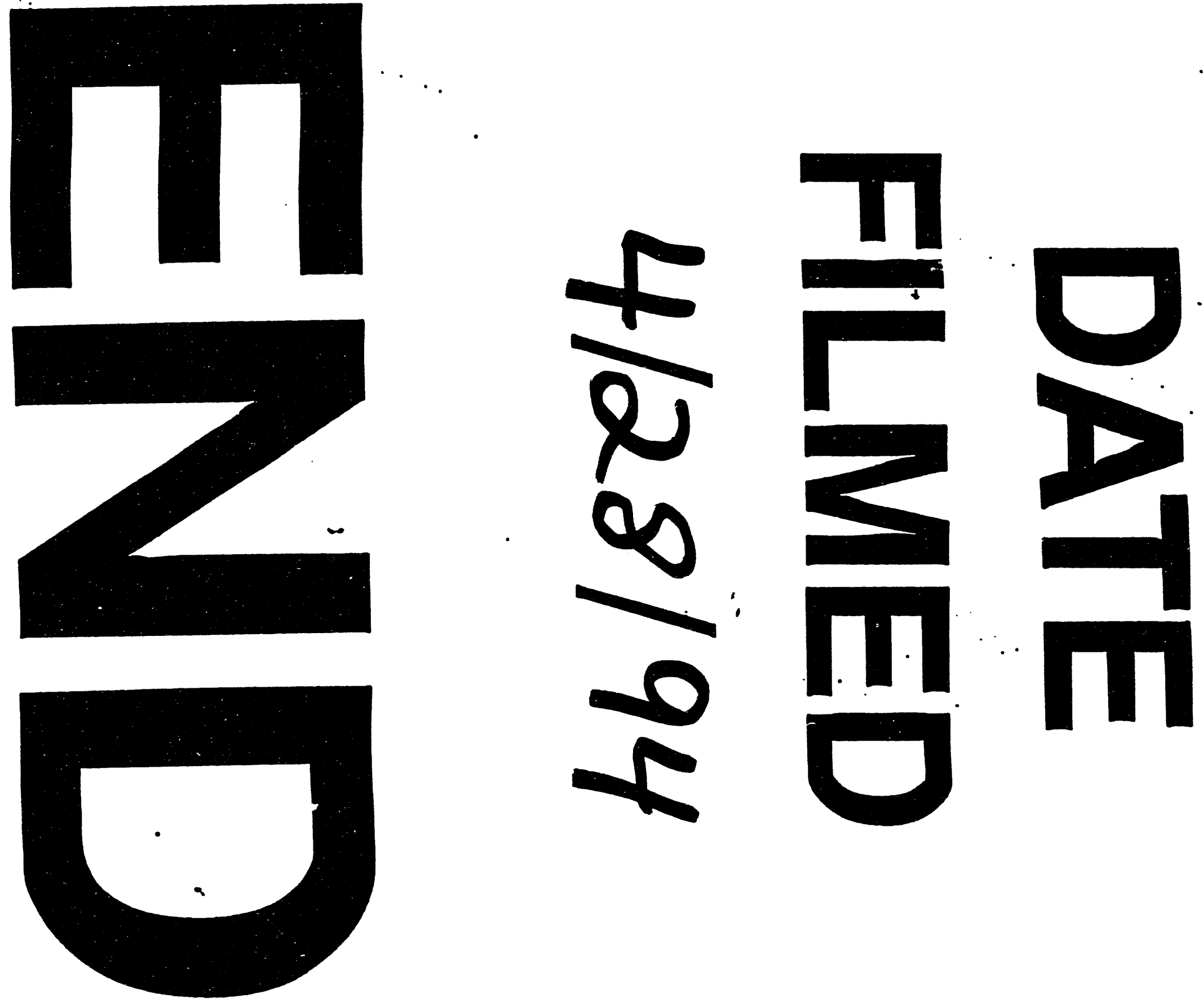

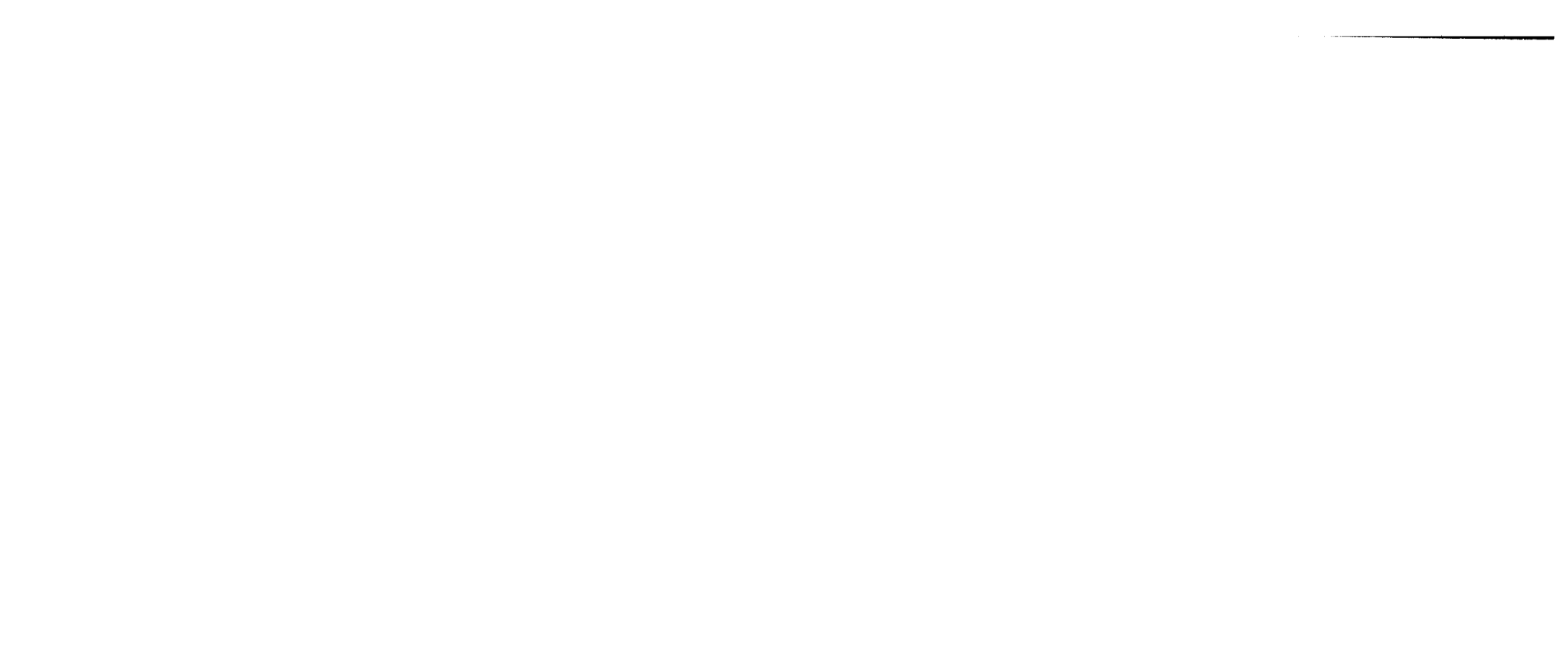

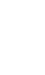
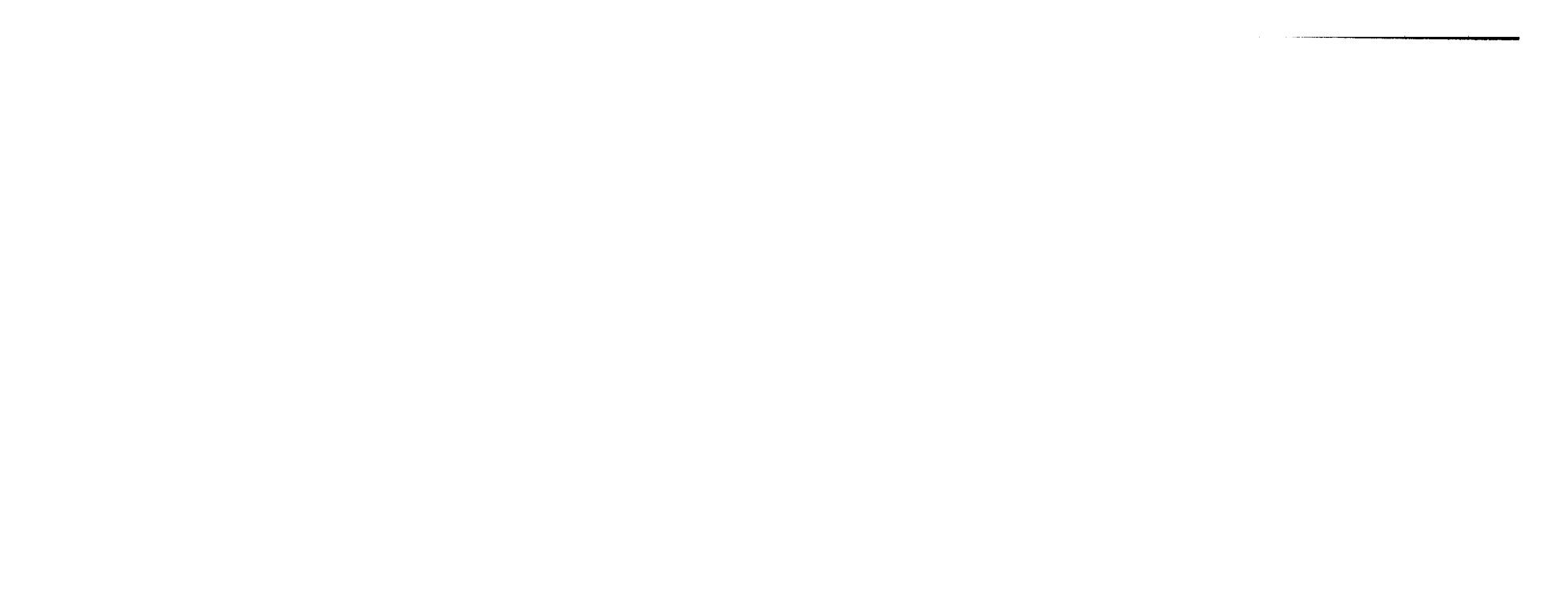